\title{
An Investigation into Current Production Challenges Facing The Libyan Cement Industry and the Need for Innovative Total Productive Maintenance (TPM) Strategy
}

\author{
Mustafa Graisa and ${ }^{1}$ Amin Al-Habaibeh \\ Advanced Design and Manufacturing Engineering Centre \\ Nottingham Trent University \\ Burton Street, Nottingham, NG1 4BU \\ Emails: Mustafa.Graisa@ntu.ac.uk, Amin.AL-Habaibeh@ntu.ac.uk
}

\begin{abstract}
Purpose- The purpose of this paper is to investigate maintenance and production problems in the cement industry in Libya with particular emphasis on future implementation of Total Productive Maintenance (TPM).

Methodology/ Approach- The paper presents the use of case study approach of production data and history, field visits, a survey methodology using a detailed questionnaire with employees and interviews with top and middle managers in four cement factories.

Findings- It has been found that the four factories under investigation have low productivity and production levels when compared with the design values. There is no clear TPM strategy and it has been also found that the lack of training and personal development is the main cause of this problem. In addition, employees are found not to be motivated as a result of the lack of poor management strategy and reward structure.

Implications- Based on the findings, a new framework for TPM has been developed. This TPM strategy could be implemented in other Libyan factories as a result of the potential similarities in the cultural and environmental aspects.

Practical implications- The current challenges have been identified and comparative analysis is developed into a model for the implementation of TPM.

Originality/Value of paper- The paper highlights limitation is the cement factories in Libya in relation to TPM and production strategies. The importance of adopting a realistic strategy and framework by managers is discussed. This work is developed as collaboration between Academia and Libyan Cement industry for solving productivity problems and develop a strategic framework of TPM for improving the Libyan industry.
\end{abstract}

Keywords- Total Productive Maintenance, Libya, Cement production.

Paper type- Research paper

\section{Introduction}

The international competition and the demand to increase productivity of manufacturing and production lines have attracted the management of industrial organisations from a wide spectrum to implement Total Productive Maintenance (TPM) as a tool for improving productivity and system's output. Total Productive Maintenance (TPM) is a maintenance program philosophy which is similar in nature to Total Quality Management (TQM) in several aspects, including the total

\footnotetext{
${ }^{1}$ Authors to who all correspondents should be addressed.
} 
commitment of upper level management to the TPM programme, employees must be empowered to take initiatives and corrective actions, and continuity and long term strategy is needed as TPM is a continuous process (Chan et al, 2005 and Shamsuddin et al, 2005). The implementation of the available technology and cultural change of employees and management are also necessary to achieve the objectives of the process. With the implementation of TPM, maintenance is no longer the necessary evil, but it is a vitally important part of the business. The general vision of TPM eliminates any 'conflict of interest' between production and maintenance departments. If the objective is to optimise the performance of the production line, it is important to integrate both activities in a comprehensive strategy. Down-time for maintenance should be scheduled as an integral part of the manufacturing process. Total Productive Maintenance is often defined as "Productive Maintenance involving total participation" (Bamber et al., 1999). The objective of TPM is the continuous improvement that embraces all aspects of an organisation. In general, and according to Sharma et al. (2006), TPM involves maximising the utilisation of equipment to establishing a comprehensive approach towards maintenance of equipment during the entire product life span, implementing TPM by various departments including production, maintenance and management, involving all employees from top management to shop-floor workers, promoting preventive maintenance through staff motivation and increasing productivity while, at the same time, improving employee morale and job satisfaction. However, implementing TPM might not be an easy task. According to Ahuja et al. (2008) several aspects could influence the successful implantation of TPM including lack of senior management support, lack of budget or investment, pressure of workload, confliction of management initiatives, inefficient use of maintenance staff and senior management's tolerance of poor performance. In recent years, Libya has focused on improving its industry in general and the cement industry in particular. Hokoma et al. (2008) have presented a comprehensive research work in relation to TQM, JIT and MRPII within the cement industry in Libya. It has been found that there was no clear strategy in relation to the above areas, see Rod et al (2008). In this paper, the authors investigate TPM and maintenance strategies in relation to the cement industry in Libya taking into consideration diversity of aspects on different management levels. Other recent publications, see for example Bindra et al. (2004) and Hokoma et al. (2006) has also presented investigations within the industry in Libya from different context. Significant research has been performed on the application of TPM in different industries in different countries, see for example Al-Muhaisen and Santarisi (2002), Tsarouhas, P. (2007), Ahuja,I.P.S. and Kumar, P. (2009), and Alsyouf, I (2009). However, it has been found that Libya has unique difference, particularly in relation to United Nation embargo on Libya and the lack of collaboration with industrially developed countries.

\section{Maintenance Strategies}

For far too long, failures of machines have been thought of as inevitable events within any production system and engineers used to consider maintenance as repair operations (Al-Muhaisen and Santarisi, 2002). There are mainly three types of machine maintenance (Kegg, 1984): unplanned breakdown maintenance, planned schedules maintenance and Condition monitoring Based Maintenance (CBM), see Figure 1. Unplanned maintenance and unpredictable failure of machines have a crucial effect on the efficiency of the production system. Low reliability of machines increases downtime, consequently causing unnecessary and unexpected costs. The planned scheduled maintenance is normally based on the statistical analysis of the 
machine failure history and maintenance recommendation of machines/spare parts manufacturers that normally include unnecessarily high factor of safety. The third type of maintenance strategies is the condition monitoring based strategy. It is a planned maintenance based upon measuring the conditions of the critical elements of the machine during operation. The analysis can be done to predict the time to failure and thus allow maintenance to be planned (Kacprzynski et al., 2000) and Khamba et al., 2008) condition monitoring can reduce breakdown costs by enhancing preventive maintenance scheduling and effectiveness of maintenance operations.

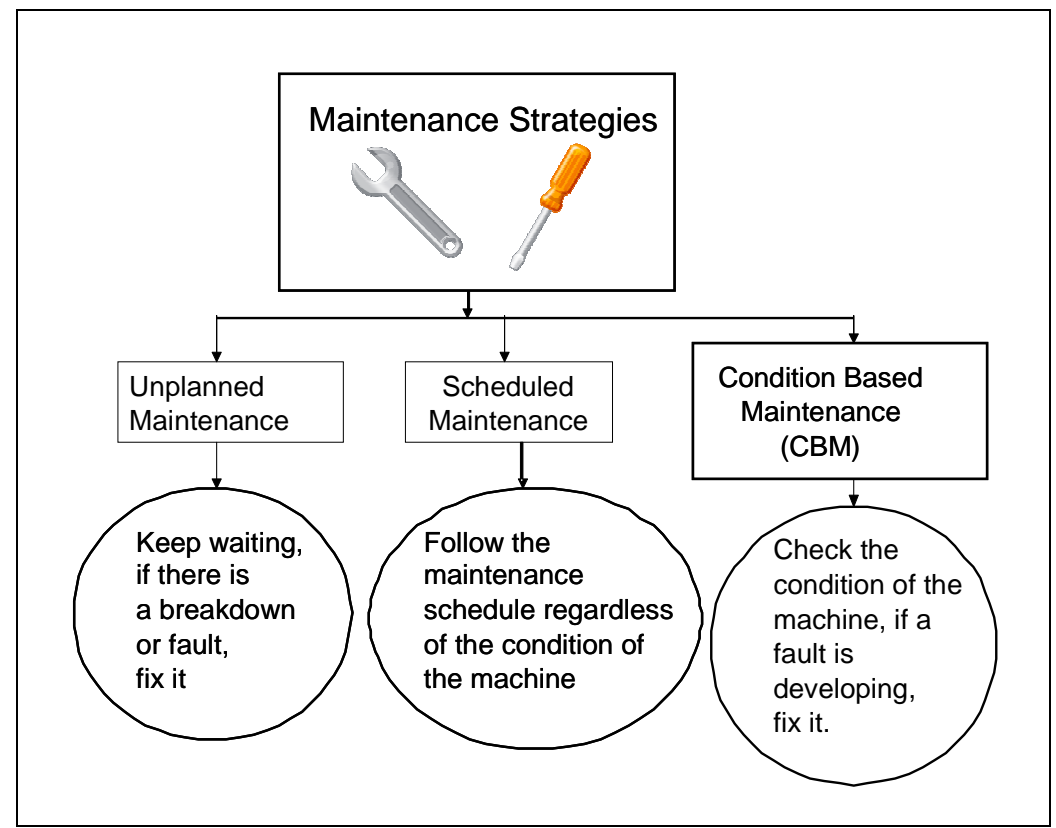

Figure 1: The main three types of maintenance strategies.

$\mathrm{CBM}$ is an evolving area of condition monitoring. According to Al-Habaibeh et al. (2004, 2005), different sensor technologies and condition monitoring systems could be used for Condition-Based Maintenance. In terms of the future of CBM, "it can be concluded that the future technical development might or should be heading towards prognostication and calculations of remaining useful life" (Marcus, 2004). TPM integrates the above maintenance strategy in a comprehensive strategy with production and select the most suitable maintenance procedure that could be used to produce the most suitable results (Al-Habaibeh et al., 2002).

\section{The Cement Industry in Libya}

Libya post 1969 has witnessed considerable industrial and urban development. City of Alkhums was one of the cities where several cement factories were built because of its strategic location and the availability of the necessary raw materials for cement production. The National Cement Company (NCC) is one of the largest companies in Libya and one of the largest producers in North Africa. NCC is located in the Northwest region of Libya. It has a cement production target of 3,330,000 tonnes per annum. NCC also has additional manufacturing facilities, for example, it also produces gypsum, lime, factory bags, factory block, marble, concrete plant and Cement mixes. The company comprises four Cement factories. The first was built in 1968 near Alkhumes (Margeb) city which is 80 miles east of Tripoli (MCF). It was 
designed for a production capacity of 330,000 Tonnes per annum. The second factory (SCF) was built in 197725 miles north of Souq Alkames, a town of Tripoli and has a target production of 1,000,000 Tonnes per annum. The third factory (LCF) was built in 1979 at Alkhumes (Libda) which is 90 miles west of Tripoli. This factory has also been designed for a production capacity of 1,000,000 Tonnes per annum. The forth factory (ZCF) was built in 1984 at Zeleten city which is about 103 miles from Tripoli. The factory is designed for production capacity of 1,000,000 Tonnes per annum. The cement produced from the four factories is for internal consumption due to the fact that the total production is required for the infrastructure of Libya. NCC produces cement according to specific Libyan specifications, which are similar to those of British Portland cement. It uses a dry process method in all factories. The management structure of NCC has a centralised management system (i.e. Head Quarter) to control all factories and plants which is located at Alkhumes city due to its central geographical position. This paper is part of a comprehensive research work which was initiated by NCC to address the problems which the company is facing and develop an improved TPM strategy to enhance productivity and reduce cost.

\section{The Investigation of the Cement Industry}

In order to help the management to identify the main problems facing the four factories and identify a suitable strategy for improving the production in the four factories a comprehensive study has been initiated which includes analysis of the historical production data and productivity, field visits to identify some the main problems, questionnaires to technical staff at all levels and interviews with middle and top managers. This paper will present and discuss the main results addressed in this investigation and more detailed will be presented in future publications. The field visits in the four factories included the main 'obvious to see' issues that could be addressed. In order to develop a good benchmark, a visit to a UK cement factory has been also included for comparison. The results see Figure 2; indicate that there are poor maintenance procedures, lack of organisation and negative effect on the environment within the Libyan factories. Figures $2-\mathrm{a}$ and 2-b indicate poor maintenance of filters in one of the factories which has negative effect on the environment. Figure 2-c indicate s a comparison between UK and one of the Libyan factories in relation to storage of material and the general organisation of the plant.

It has been found that there clear need for using the Five S's methodology to focus on organisation, cleanliness and standardisation to improve profitability, efficiency, service and safety. Figure 2-d indicates the health of some of the equipment and the level of maintenance within the factory. From the field visits, it has been found that there is significant need to implement TPM within the Libyan cement industry to provide high productivity and improve maintenance strategy. Based on the initial field work, analysis of the historical production data has been collected and analysed, as described in the next section, in order to understand the history of the four factories and in order to develop a comprehensive view and analysis. 


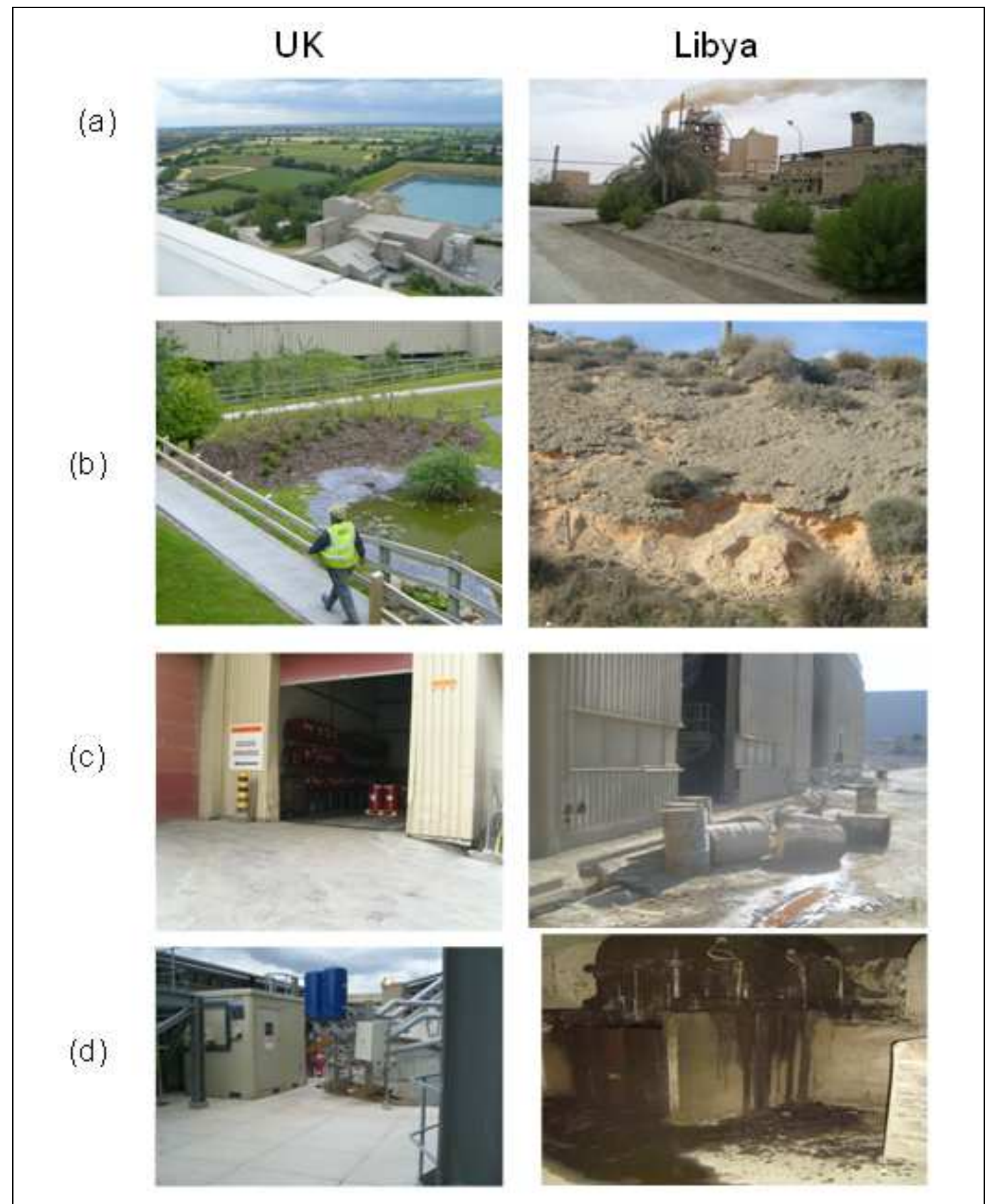

Figure 2: Filed visits and comparison between a UK cement factory and some of the cement factories in Libya.

\subsection{Analysis of productivity data - a case study}

Figure 3 presents the production (in thousand Tons) of the four factories between 1993 and 2006 as obtained from the company's production data reports. It is clear that there is significant variation in the production over the years. It has been found that the majority of the fluctuation in the production of the factories is based on changing in shift hours, failure of equipment and lack of spare parts, etc. It has been found for the analysis that there is clear indication that there is a need for TPM in order to maintain production on a stable and productive level. 


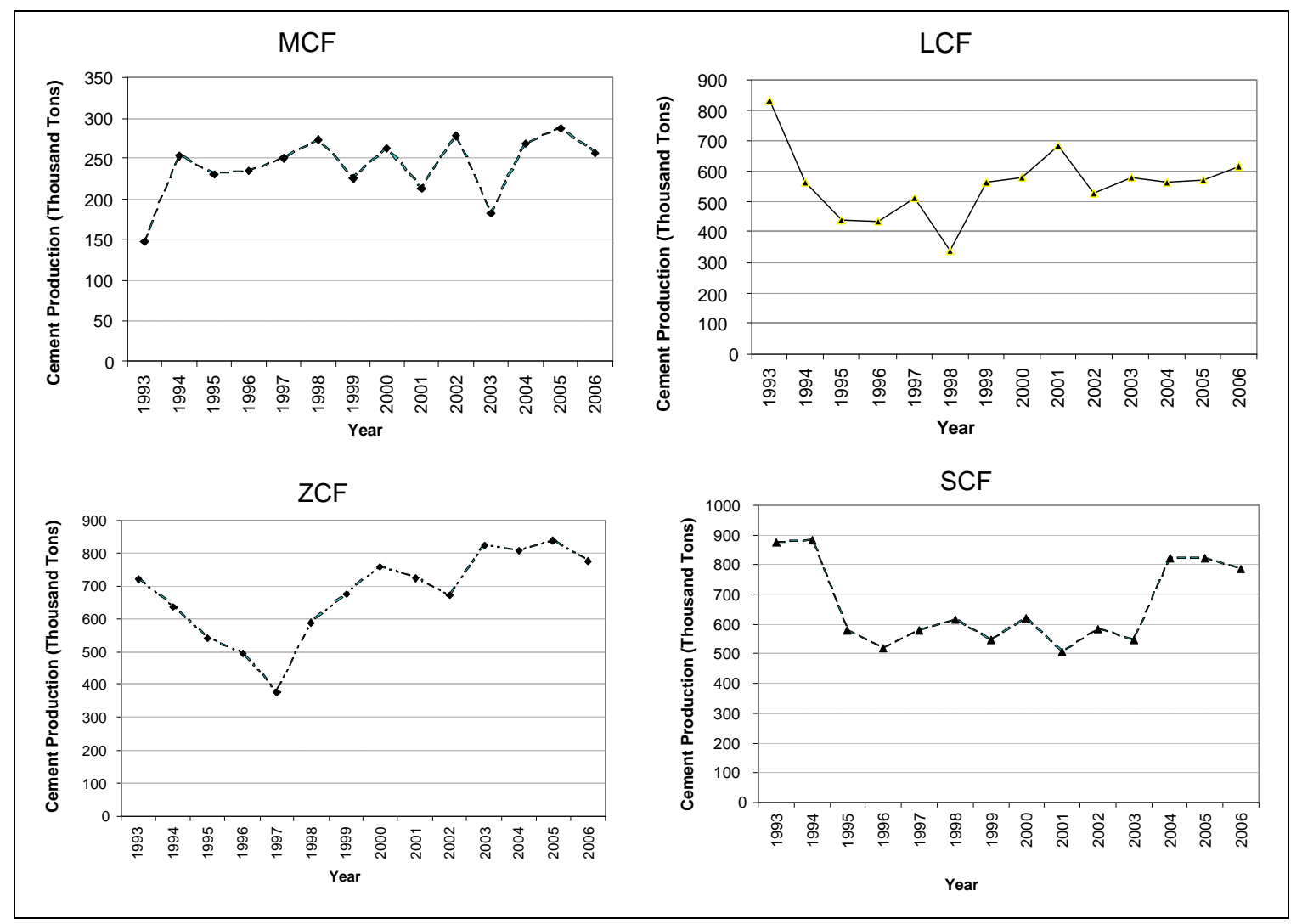

Figure 3: The production of the four factories between 1993 and 2006.

In this paper, the data from LCF will be analysed in detail to represent examples of some of the common problems in the four factories. The Libdah factory (LCF) is designed to produce $1 \mathrm{M}$ tonnes annually (based on 24 hours a day operation), in order to satisfy some of the local consumption of cement in Libya. Figure 4 presents the production of the Libdah factory from 1981 to 2008. The actual production in the factory started in 1981 with a production of $0.47 \mathrm{M}$ Tonnes, which was less than $50 \%$ of the design capacity of the factory. This is related mainly to the need for experienced workers and training of employees. There was lack of focus on maintenance strategies or maintenance training at the start of production. Between 1982 and 1983 the production increased to about 0.7 M Tonnes (point A on Figure 4). However, the production dropped down between 1984 and 1986 reaching its lowest level of about $0.22 \mathrm{M}$ Tonnes (point B). This drop was mainly caused by the need for maintenance experience and strategies which were needed to maintain the factory to the right standard. As a results of the problem, new group of maintenance and production engineers where employed to improve the factory's performance. There was steady increase in the production of the factory between 1986 and 1993 (between points B and C). During 1993 (point C), the factory had reached its maximum production level of about $0.84 \mathrm{M}$ Tonnes. This simply was the maximum capacity that theoretically could be achieved from the factory based on the actual 20 hours operation a day. 


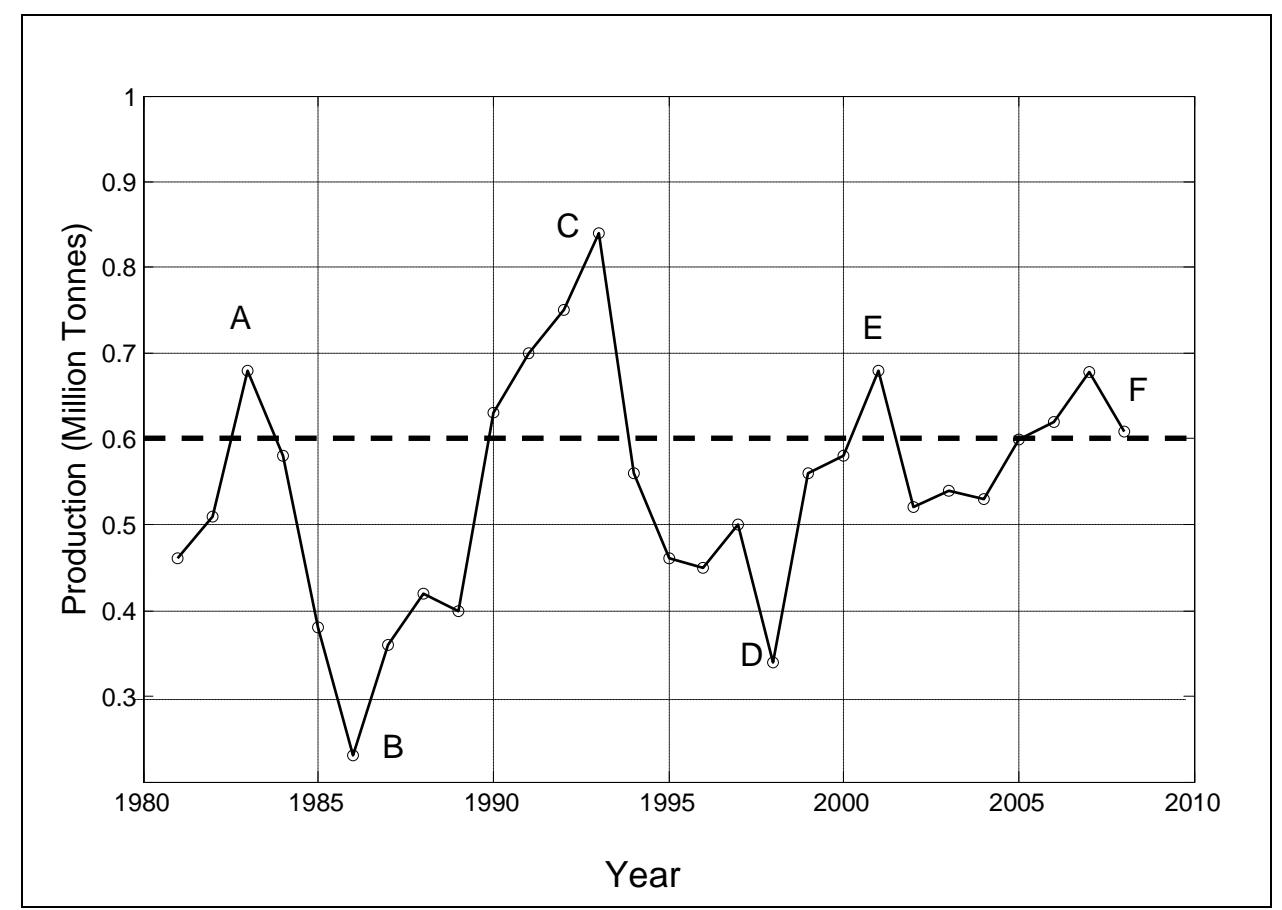

Figure 4: Cement production in million tonnes in Libdah factory.

The main reason of achieving this maximum productivity was the introduction at the end of 1992 to a new department to the factory, named (Maintenance Research and Development) which focused on the development of integrated production and maintenance strategies with Total Productive Maintenance as the main aspect of the strategy. The new department realised that the factory had two shifts only ( 8 hours each). The factory operated from 7 AM to 11PM. This meant that the factory had been working at a maximum production level of about 67\%. (i.e. $0.67 \mathrm{M}$ Tonnes annually). Each shift normally included one technician, two electrical engineers, three mechanical engineers and four general service workers. Without the use of any additional resources, the new management changed the culture of the factory by introducing three shifts and extending the working hours of the factory into 20 hours and raising the theoretical production capacity of the factory into about $84 \%$ (i.e. 0.84 M Tonnes Annually). In order to create the motivation and incentives to the new shift culture, the production of each shift was monitored and displayed on a production sheet in the factory. The management awarded the shift with efficient and highest production a certificate of achievement which was displayed in the factory. Moreover, another certificate of achievement was given to the shift with maximum production on monthly basis. The staff of that shift were awarded an individual 'Champion Certificate'. Additional two days leave were given also to the Champions to reward them for their hard work. This created an innovative and dynamic environment where staff worked hard and enjoyed the rewards and incentives. Problems and bottlenecks were solved based on lean manufacturing, effective maintenance and self-motivation.

This achievement was performed on local management level without the need for any additional resources. At the beginning of 1994, a new management structure came to place, which resulted in removing incentives, empowerment and self-motivating culture of weekly and monthly certificate of achievements and the additional holidays. This resulted in staff refusing to work overnight shifts and the factory was limited to 
two shifts with 16 hours of operation a day in total (67\% maximum production). In addition to this, the new management did not have a clear production and maintenance strategy which resulted that technical staff were reassigned to do marginal tasks within the factory. This lead to having the production going into steep decline between 1993 and 1998 (between points C and D on Figure 4). Moreover, The United Nation embargo on Libya during that period did not help the factory to obtain the necessary spare parts and equipment. Naturally the management, in response to the decline in production, had managed to increase the productivity (point E) using the same two shifts system. However, the three shift culture and increasing the working hours has been difficult to re-achieve due to the lack of staff incentives, empowerment and rewarding system. Recent production Figures (Point E on the graph) indicates about $60 \%$ of production level only. Similar aspects has been found when studying the history of the other three factories which clearly indicate lack of operation and maintenance strategy, the need for training and the lack of staff motivation for 24 hours operation within the factory.

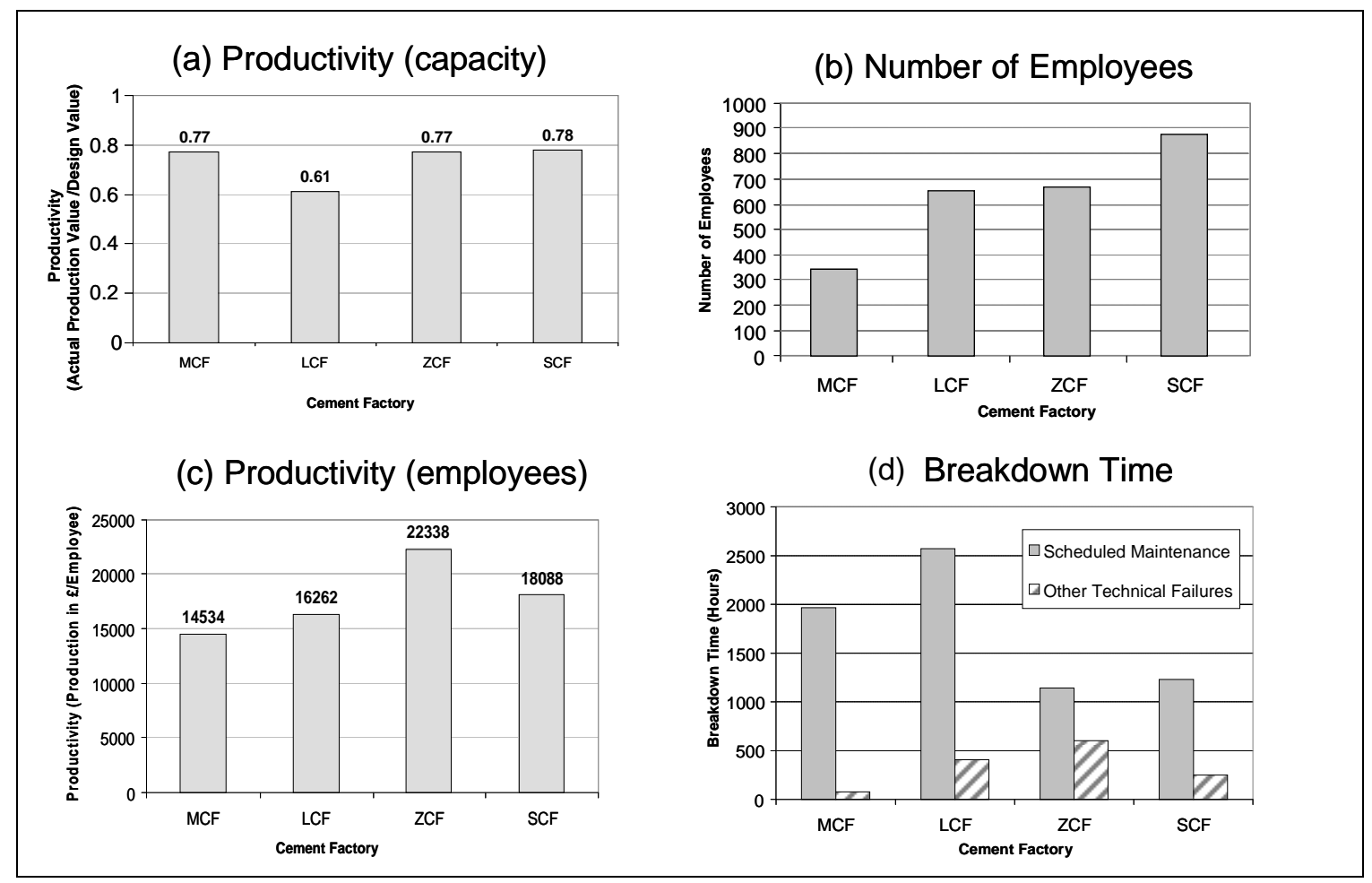

Figure 5: Analysis of production Figures for 2006

Taking 2006 as a bench-mark year for the four factories, from Figure 5-a it can be seen that efficiency of the factories do not exceed $78 \%$ of the design capacity with an average of $73 \%$. This indicates a loss of about 891 thousand Tonnes per annum which a loss of about $£ 35 \mathrm{M}$ assuming that a $50 \mathrm{Kg}$ cement bag is sold for about $£ 2$ locally. Figure 5-b presents the number of employees in each factory. MCF has lower production capacity than the rest which is reflected in a lower number of employees. LCF and ZCF have similar number of employees while SCF has much higher number of employees despite the fact that it has similar capacity. This is reflected in the productivity level per employee as shown in Figure 5-c. Figure 5-d presents the stoppage/breakdown time of the four factories for 2006. Notice that there is about 
7000 hours of scheduled maintenance and about 1800 hours of unplanned breakdown. This is considerably very high which is on average about 10 weeks per factory.

\subsection{Questionnaire}

In order to understand in detail the complete aspects of the four factories and to help the management of the company to take suitable decisions regarding the improvement of productivity and TPM, a survey questionnaire is selected to be one of the research methodologies. The questionnaire is designed particularly for engineers and technicians within the four factories.

The questionnaire is design to take into consideration the following aspects on productivity:

1. Operational aspects including productivity, procedures, raw materials, transportation and processing plant.

2. Maintenance; in terms of maintenance strategy, inspection, cleanliness and availability of maintenance tools and equipment.

3. Human aspects including incentives, training, personal health and safety.

4. Environmental and health issues; in terms of waste management, emissions, pollution, emergency procedures.

The questionnaire is designed for engineers/technical staff. A total of 160 questionnaires were distributed and 130 engineers/technical staff responded, which makes the response rate to be about $81 \%$. This indicates that the majority of the engineers/technical staff are interested to participate in any studies to improve the working environment and enhance the productivity of the factories. Cronbach's Alpha is found to be $91.0 \%$ using SPSS software which indicates the reliability and consistency of the questionnaire. The terms engineers and technical staff are used in this paper interchangeably.

\section{Result of Questionnaire}

Table 1 explores some of the operational issues in the four factories. Only 55.5\% of staff considers themselves to have sufficient practical experience which indicates lack of training as well as significant staff turnover on the shop floor. This could be as a result of the working conditions in cement factories as well as the insufficient payment. About $24 \%$ of staff believes that there is a need for more technical staff in the factory. However, when compared with other international factories, the number of technical staff is much higher, but there could be a need to improve their efficiency and technical capabilities. There appears to be lack of completion and monitoring of operational reports including calibration of monitoring and control equipment. Table 1 also indicates that there could be potential problem in the communication between the control room and staff on site/shop floor. It has been found during the field visits that communication equipment (e.g. mobile phones/ wireless communication) are not widely used within the factories. Also on-line and real-time monitoring of data from equipment and machinery through the control room is not widely implemented. There is lack of lighting at night during night shifts which could cause poor monitoring, process calibration and fault diagnostic. Electrical failure from production data seems to have very low effect on the productivity. For example, in 2006 the nonproductive time as a result of the electrical power cuts is much less than the schedule maintenance as described in Figure 5. 
Table 1: Operations and Process.

\begin{tabular}{|c|c|c|c|}
\hline Operations and Process. & $\begin{array}{c}\text { Yes } \\
\%\end{array}$ & $\begin{array}{l}\text { No } \\
\%\end{array}$ & $\begin{array}{c}\text { Don't } \\
\text { Know \% }\end{array}$ \\
\hline $\begin{array}{l}\text { Do you consider yourself a technician/engineer with sufficient } \\
\text { practical experience? }\end{array}$ & 55.5 & 33.8 & 10.7 \\
\hline $\begin{array}{l}\text { The number of skilled engineers/technicians in the production } \\
\text { area is sufficient }\end{array}$ & 57.0 & 24.5 & 18.5 \\
\hline Operation reports are completed by engineers/technicians & 63.9 & 20.0 & 16.1 \\
\hline $\begin{array}{l}\text { Control and monitoring devices and equipment are inspected } \\
\text { and calibrated regularly } \\
\text { Is the communication process to and from the control room }\end{array}$ & 63.0 & 21.6 & 15.4 \\
\hline available throughout the plant? & 44.0 & 41.4 & 14.6 \\
\hline $\begin{array}{l}\text { Have you had sufficient training on the operational aspects of } \\
\text { the factory? }\end{array}$ & 41.5 & 41.5 & 17.0 \\
\hline Lighting, particularly night lighting, at the plant sufficient & 40.0 & 44.0 & 16.0 \\
\hline External electrical power cuts have an effect on the factory & 46.2 & 38.0 & 15.8 \\
\hline
\end{tabular}

Table 2 addresses the training and personal development issues. There is a clear lack of training in the four factories where only $19 \%$ indicates that they have received training. The majority of staff believes that training courses will be useful to them. Only $2.3 \%$ have had training on TPM and only $13 \%$ believes that TPM is being applied in their area. There is clear indication from Table 2 that training is one of the main issues that should be addressed to improve productivity particularly that only $5.4 \%$ of engineers/technicians have been taking training on international level outside the country.

Table 2: Training and Development

\begin{tabular}{lrrr}
\hline Training and development & \multicolumn{1}{c}{$\begin{array}{c}\text { Yes } \\
\%\end{array}$} & \multicolumn{1}{c}{$\begin{array}{c}\text { No } \\
\%\end{array}$} & \multicolumn{1}{c}{$\begin{array}{c}\text { Don't } \\
\text { Know } \\
\%\end{array}$} \\
\hline $\begin{array}{l}\text { Have you received training courses in your field at the } \\
\text { factory? }\end{array}$ & 19.0 & 68.0 & 13.0 \\
Do you think training courses will be useful? & 70.7 & 8.0 & 21.3 \\
Will you need other training courses in the future? & 69.3 & 11.0 & 19.7 \\
Do you have knowledge of the TPM programs? & 14.6 & 70.0 & 16.4 \\
Have you attended any courses in relation to TPM? & 2.3 & 76.0 & 21.7 \\
Is the TPM program being applied in your work area? & 13.0 & 73.0 & 14.0 \\
Have you had any international training courses outside your & & & 74.0 \\
country? & & & 20.6 \\
\hline
\end{tabular}

In relation to maintenance procedures, Table 3 indicates that there is lack of clear maintenance programme (preventive/scheduled). Only 50\% of staff believes that the number of technical staff for maintenance is sufficient. There seems to be no clear system of recording maintenance procedures and results and it mainly being done on ad-hoc basis. $63 \%$ of engineers/technicians believe that there is no programme for routine and scheduled maintenance and $66.3 \%$ believe that there is no preventive maintenance programme in place, which indicates poor preventive maintenance system. $51.5 \%$ of technical staff believes that there is no calibration programme in 
place and $21.5 \%$ do not know if there is one. This clearly indicates lack of knowledge and training in this area, particularly that only $40 \%$ have experience in control and monitoring devices.

Table 3: Maintenance procedures and calibration.

\begin{tabular}{|c|c|c|c|}
\hline Maintenance schedules & $\begin{array}{c}\text { Yes } \\
\%\end{array}$ & $\begin{array}{l}\text { No } \\
\%\end{array}$ & $\begin{array}{l}\text { Don't } \\
\text { Know } \\
\%\end{array}$ \\
\hline $\begin{array}{l}\text { There is a program for routine and scheduled maintenance in } \\
\text { place }\end{array}$ & 21.6 & 63.0 & 15.4 \\
\hline There is a program for preventive maintenance in place & 20.7 & 66.3 & 13.0 \\
\hline $\begin{array}{l}\text { The number of skilled technicians to conduct maintenance is } \\
\text { sufficient }\end{array}$ & 50.0 & 34.7 & 15.3 \\
\hline $\begin{array}{l}\text { There is a system for recording maintenance of equipment and } \\
\text { machinery? } \\
\text { Is there a program for the inspection of machinery and }\end{array}$ & 43.8 & 41.2 & 15.0 \\
\hline & 43.0 & 37.6 & 19.4 \\
\hline factory? & 52.3 & 33.0 & 14.7 \\
\hline Spare parts are available & 61.5 & 21.5 & 17.0 \\
\hline $\begin{array}{l}\text { Have you received training in inspection procedures equipment } \\
\text { and machinery? }\end{array}$ & 25.3 & 56.3 & 18.4 \\
\hline Are written reports on the process of inspection submitted? & 68.0 & 14.3 & 17.7 \\
\hline Are the inspection reports filed and acted upon? & 67.0 & 14.0 & 19.0 \\
\hline $\begin{array}{l}\text { Are inspection carried out by trained and experienced } \\
\text { inspectors? } \\
\text { Do you have a program for the calibration of instruments and }\end{array}$ & 66.1 & 12.4 & 21.5 \\
\hline $\begin{array}{l}\text { equipment? } \\
\text { Do you have sufficient experience in control and monitoring }\end{array}$ & 27.0 & 51.5 & 21.5 \\
\hline devices? & 40.0 & 42.3 & 17.7 \\
\hline
\end{tabular}

When investigating the human aspects and job satisfaction, Table 4 indicates that the majority of staff are satisfied with the working social environment. However, there seems to be lack of financial incentives and job satisfaction. $46 \%$ would like to move to another job while $64.7 \%$ work outside the working hours to meet their financial demands. Only about $21.6 \%$ of staff feels that their monthly salary is sufficient to meet their financial needs. From Table 4 it could be concluded that there is lack of financial invectives to workers and the majority have to work externally or additional hours to satisfy their financial needs. In this case, it will be difficult for workers to be sufficiently motivated to do the required work. 
Table 4: Human-factors and Job Satisfaction

\begin{tabular}{|c|c|c|c|}
\hline Human factors and Job Satisfaction & $\begin{array}{l}\text { Yes } \\
\%\end{array}$ & $\begin{array}{l}\text { No } \\
\%\end{array}$ & $\begin{array}{c}\text { Don’t Know } \\
\%\end{array}$ \\
\hline Do you feel that you are treated fairly at the factory? & 70.0 & 14.6 & 15.4 \\
\hline Are you happy with your work? & 64.0 & 25.3 & 10.7 \\
\hline $\begin{array}{l}\text { Are you included in recreational activities organised by the } \\
\text { factory? }\end{array}$ & 8.7 & 72.3 & 19.0 \\
\hline Does your salary include a performance related incentive? & 13.0 & 71.5 & 15.5 \\
\hline Do you want to move to anther job role? & 46.0 & 35.5 & 18.5 \\
\hline Is your monthly salary in the plant sufficient? & 21.6 & 60.0 & 18.4 \\
\hline Do you undertake external work to meet your financial needs? & 64.7 & 23.0 & 12.3 \\
\hline Is overtime available within the factory for you to work? & 68.4 & 14.6 & 17.0 \\
\hline $\begin{array}{l}\text { Do you receive other benefits from your work (e.g. company } \\
\text { car)? }\end{array}$ & 14.3 & 68.0 & 17.7 \\
\hline
\end{tabular}

In relation to environmental issues and pollution, as indicated in Table 5, 43\% think that the chemical waste is not disposed of in an environmentally friendly manner despite the fact that $62.3 \%$ believe that there is a policy for recycling within the factory. The surprising fact is that $98.5 \%$ of employees believe that there is no programme of recycling office waste or they are not aware of it. On average, only about $65 \%$ believe that oil and other hazardous materials are disposed of in an environmentally friendly manner.

Table 5: Environment, pollution and Waste

\begin{tabular}{|c|c|c|c|}
\hline Environment, pollution and Waste (garbage) & $\begin{array}{l}\text { Yes } \\
\%\end{array}$ & $\begin{array}{l}\text { No } \\
\%\end{array}$ & $\begin{array}{r}\text { Don't } \\
\text { Know } \\
\%\end{array}$ \\
\hline $\begin{array}{l}\text { Are waste chemicals such as paint, grease, etc. disposed of in } \\
\text { an environmentally appropriate manner? } \\
\text { Is there a policy for re-using or recycling of materials such as } \\
\text { iron, cardboard, wood and empty cement bags? } \\
\text { Is there a program for recycling normal office waste (e.g. } \\
\text { paper)? } \\
\text { Are oils /greases used and disposed of in an environmentally } \\
\text { appropriate manner? } \\
\text { Are hazardous materials disposed of in an environmentally } \\
\text { suitable manner? }\end{array}$ & $\begin{array}{r}40.7 \\
62.3 \\
1.5\end{array}$ & $\begin{array}{l}43.0 \\
30.0\end{array}$ & 16.3 \\
\hline
\end{tabular}

Table 6 presents the measures taken to reduce air pollution. $74 \%$ believe that gases emitted from Chimneys are not measured. This fact is evident from the field work when visiting the four factories. Only $29.3 \%$ believe that filters operate at high standards while $47.1 \%$ believe that spare parts of filters are available. However only $36.4 \%$ believe there is a programme for maintenance of filters. For all questions below, on average $18 \%$ of employees are not aware of procedures or availability of parts. 
Table 6: Smoke and gases

\begin{tabular}{|c|c|c|c|}
\hline The smoke and gases & $\begin{array}{l}\text { Yes } \\
\%\end{array}$ & $\begin{array}{l}\text { No } \\
\%\end{array}$ & $\begin{array}{r}\text { Don't } \\
\text { Know } \\
\%\end{array}$ \\
\hline Are waste gases/dust emerging from the flue measured? & 0.6 & 74.0 & 25.4 \\
\hline Do the filters operate to a high standard? & 29.3 & 60.0 & 10.7 \\
\hline Are spare parts for filters available? & 47.1 & 36.0 & 16.9 \\
\hline Is there a program for filter maintenance? & 36.4 & 44.6 & 19.0 \\
\hline
\end{tabular}

In relation to health and safety, Table 7 presents the main result found where $67.6 \%$ confident that there is a programme for occupational safety. In total about one third of technical employees believe that there is no programme in place in relation to health an safety or they are not aware of it. In both cases, this is an issue that should be considered responsively by the factories to address any health and safety training. It seems that there is no clear process in place to monitor the use of safety related clothes and equipment since $90.7 \%$ either not aware of any measures or believe that they do not exist. On the positive side, about $80 \%$ do wear protective equipment, more than $50 \%$ of workers have received first aid training, $66 \%$ receive annual medical examinations and $79 \%$ are covered by as suitable health insurance. Also, $81.6 \%$ know the location of first aid kit, more than $85 \%$ know the location of fire fighting equipment and $82.3 \%$ are aware of the existence of medical clinic within the factory. In general, only $61 \%$ believe that they had health and safety induction.

Table 7: Health, Safety and emergency systems.

\begin{tabular}{lrrr}
\hline Health and Safety & \multicolumn{1}{l}{$\begin{array}{l}\text { Yes } \\
\%\end{array}$} & \multicolumn{1}{c}{$\begin{array}{c}\text { No } \\
\%\end{array}$} & $\begin{array}{r}\text { Kon't } \\
\text { Know } \\
\%\end{array}$ \\
\hline Do you have a program for occupational safety? & 67.6 & 19.4 & 13.0 \\
Is there any penalty or measures in place for failure to wear & 9.3 & 74.6 & 16.1 \\
protective equipment and clothes? & 50.7 & 37.0 & 12.3 \\
Have you obtained a training course in first aid? & 84.0 & 3.9 & 12.1 \\
Do you wear protective clothes/ equipment during your work? & 66.0 & 15.6 & 18.4 \\
Do you have an annual medical examination? & 79.0 & 2.6 & 18.4 \\
Is your job covered by insurance? & 81.6 & 3.0 & 15.4 \\
Do you know the location of the first aid kit ? & 85.4 & 0.0 & 14.6 \\
Do you know the location of the fire fighting equipment ? & 82.3 & 0.7 & 17.0 \\
Is there a specialist clinic with a doctor in place? & 61.0 & 19.3 & 19.7 \\
\hline Did you have health and safety induction? & &
\end{tabular}

\subsection{Interviews}

The main points from the questionnaire where formed the basis of a semi-structured interviews with 15 top and middle managers in the company and the four factories. The problems/finding that are identified during the interviews could be summarised as follows:

- Raw materials is available but with impurities and there is no clear strategy for testing the materials and staff need personal development and training. 
- Staff lack the training and there is no clear strategy for that in the company.

- Salary is not sufficient and employees sometimes undertake external work to improve their income.

- There is insufficient training in relation to maintenance and inspection procedures and programmes.

- There is a need for training and clear strategy for cleaning and lubrication of equipment is such dusty environment.

- Machines are not cleaned or maintained regularly.

- Waste bins are not available for recycling of normal waste.

- No clear system in place for emergency procedures.

- Significant training is needed for preventive maintenance strategy.

- There is deficiency in training culture for daily maintenance programmes.

- Maintenance data is not recorded in the correct way and training is required.

- Employees do not get performance-related incentives

- The majority of staff would like to leave the company if the situation stays as is.

- No organisation of social activity within the company and no clear policy towards that.

- Staff do not attend training courses in relation to maintenance and there is no clear personal development system in place.

- There is no clear system in place to measure pollution and there is not healthrelated monitoring programme for staff.

\section{Discussion}

The findings of this research work has identified that productivity levels and the implementation of TPM are at modest and poor levels. The field visits in Libya and UK has identified a huge difference in culture, productivity, cleanliness and environmental awareness. Part of this could be related to European and British standards, particularly that the British cement factory which was visited as benchmark was in a residential area in comparison with the Libyan factories. It has been found that the Libyan factories lack some of the employment of modern and well established procedures such as continuous improvements, preventive maintenance, six sigma and the 5-S practice (Structures, Systemise, Sanitise, Standardise and Self-discipline). There is clear evidence of high level of gas pollution and the effect of that on the environment. There was also evidence of poor maintenance of equipment in general including preventive/planned maintenance. It was evident also that the shop floor workers do not use protective equipment on regular basis particularly the use of masks and reflective jackets.

The analysis of historical production data indicates that the four factories operate at very low production rate in comparison with the design capacity of the factories. High level of fluctuation has been found in the four factories as a result of insufficient operational training, lack of maintenance training and lack of spare parts.

The main findings of the questionnaire is the lack of training (operational and maintenance), lack of incentives for improvements and the lack of personal development system. In general health and safety response is found to be better than other areas within the factory. The interviews have confirmed some of the major 
issues in relation to training, financial incentives, pollution measurements and lack of social activities.

There could be many issues and steps that could be taken to improve this current situation. In terms of the environmental aspects, much legislation could be put in place by the government and local authorities to force factories with similar profile to take positive measures regarding pollution and health and safety. However, roles and regulations which could theoretically be already in place, might not be sufficient to improve the situation on practical basis and more positive attitude from factories is required including Corporate Social Responsibility.

In terms of productivity, the system's productivity could be increased by investing more heavily into modern equipment, training and suitable TPM strategy whether this involves complete systems or more for maintenance and monitoring equipment. However, as we have seen from the past statistical data, this might not guarantee a high productivity if the human aspect is not taken into consideration. The lack of training, motivation and the possible resistance attitude of staff can drastically restrain productivity.

The maintenance aspect of the business is still poor and based on 'fire-fighting' scenarios rather than building a clear strategy. However, it is believed that lack of training and motivation could be the main reason for poor maintenance practice and the negative attitude of the majority of the technical staff, particularly when considering the lack of performance-related payments and the insufficient salary they receive. Many of technical staff have answered 'don't know' for basic and obvious question, which could also indicate some carelessness or lack of trust between staff and senior management.

From the above discussion, it is believed that the main aspect in order to improve productivity is to focus on the human aspect of the business. This could be in terms of the internal side of the company or the external side of the business (i.e. with the society, government departments and other organisations).

It can be argued that improving the human aspect by ensuring that employees understand what is expected from them and giving them the freedom to become proactive within the company. It is believed that the lack of self satisfaction and rewarding system could be the main drawbacks to productivity improvement. Establishing an effective link between employees' training and strategic planning is one of the most important challenges facing the company that should be addressed. From the finding, it seems that there is a lack of strategic planning on different levels within the factories, and hence it has been difficult to implement long term planning.

Most important is to enhance personal contact between senior management and workers either informally or through conferences/workshops. Emphasis could be placed on group development, section leaders being called upon to improve communications within their section.

The significance of this research work is in the development of a Framework to prepare the cement factories into the implementation of modern TPM via CPMS 
(Comprehensive Productivity and Maintenance System). The production systems need to be addressed and improved to be at minimum level or requirements to be able to apply modern methods and techniques. If you imagine, productivity research as a pyramid, as shown in Figure 6, most modern research in the $21^{\text {st }}$ century is targeted towards the "tip of the pyramid to achieve an optimised performance for an already existing high productivity production systems with modern technologies and management strategies. The less developed countries, such as Libya, will find it difficult to implement such modern techniques and strategies, because the production system could be described as being at the 'base of the pyramid'. The attempt to implement too advanced techniques and strategies for the existing systems could lead to an unstable system that is difficult to implement. The argument that less developed countries could use 1950's and 1960's strategies and technologies, might not be as simple as it seems. The $20^{\text {th }}$ century strategies and technologies were implemented in different culture, technological environment and political system. Hence, the $20^{\text {th }}$ century strategies could be described as a 'pyramid in a different dimension' as described in Figure 6. In simple terms it might be difficult to implement productivity strategies that were implemented in Japan in 1980's, for example, in Libya in 2010.

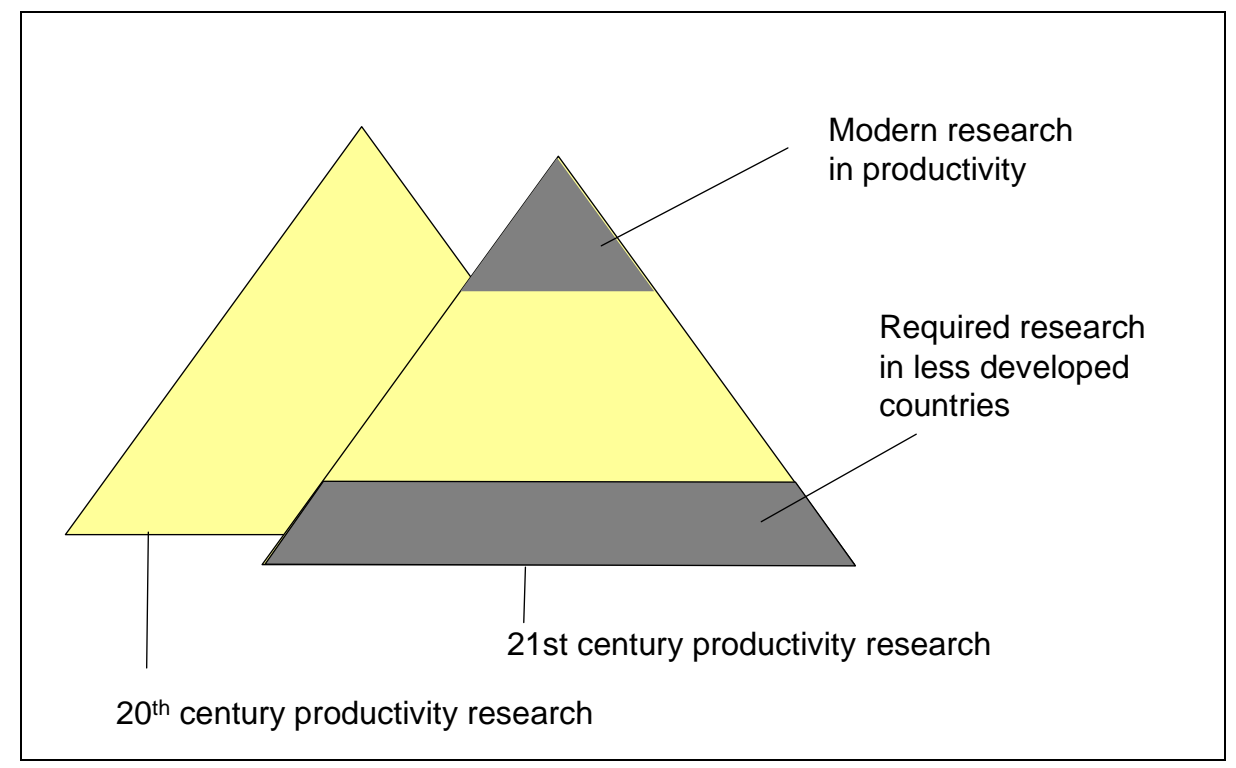

Figure 6: Comparison between modern research in productivity and the requirements of less developed countries.

One of the findings of this research is that the problem associated with the communication of problems and the sensitivity towards criticism. One of the solutions provided in this thesis and identified in the framework is the involvement of external organisations, such as universities, to act as a consultant in order to avoid any internal problems between employees and management.

When the comparative study between UK's and Libya's factories was presented for the Libya factories, it acted as an 'eye-opener'. The Libyan factories showed their interest to use the study as a training course for employees and management to show a positive benchmark that the Libyan factories could aspire to achieve. The identification of important internal and external factors that should be addressed to improve training and motivation is on of the important aspect. 
General management aspects could be directed to develop an effective framework that can be developed to address the problems in the four factories. Strategic planning and the management of the organisation's culture are the two key elements that should be addressed when developing the solution for the current problems. Figure 7 presents a novel approach to address the problems in the four factories. The new approach builds on three main aspects: staff training, staff motivation and the environment. This leads to the new concept of Comprehensive Productivity and Maintenance Strategy (CPMS) that will feed into TPM Strategy which will lead into improving productivity and enhance profitability.

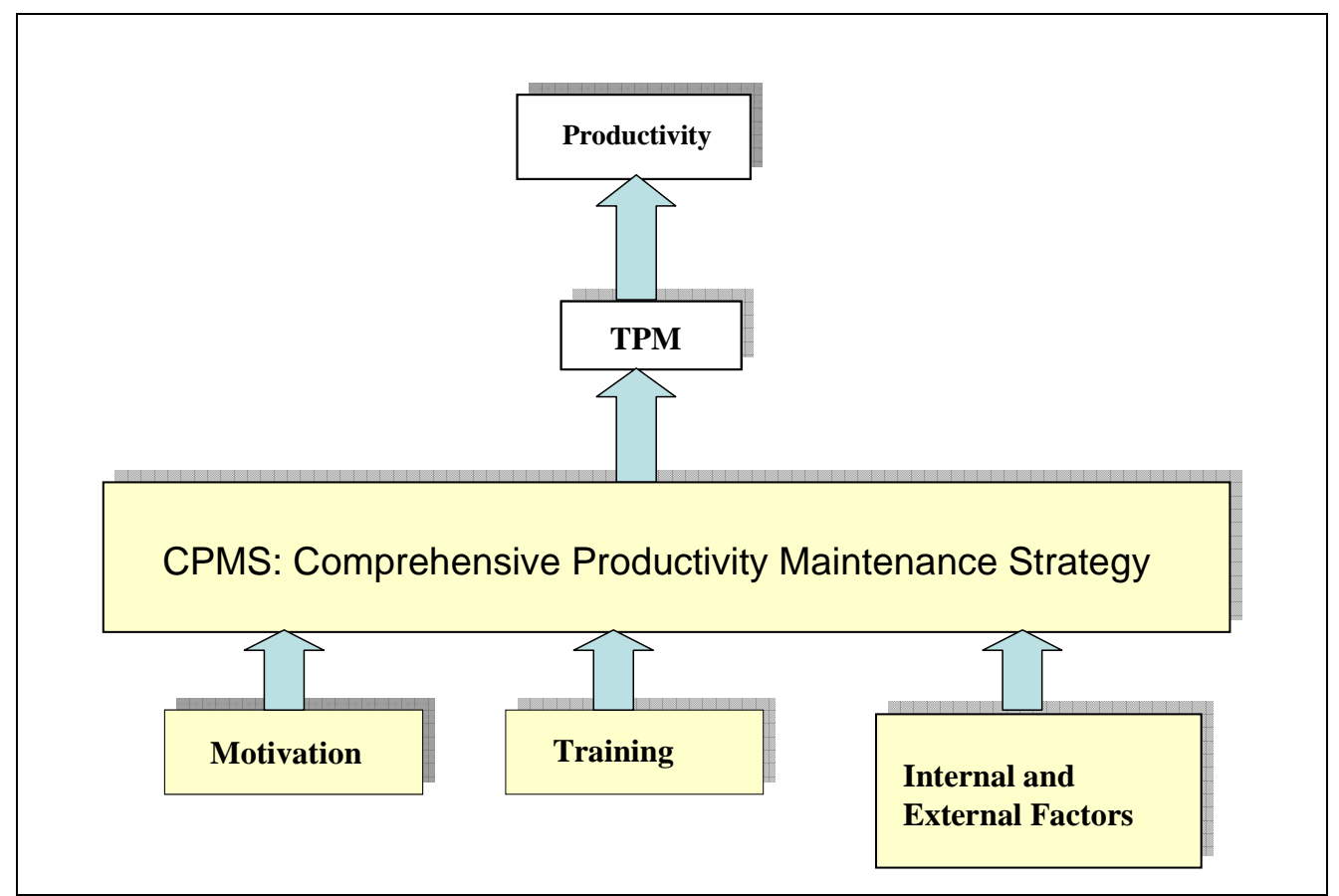

Figure 7: The novel model that is generated to solve the cement factories

problems.

In order to solve the problem facing the company and the four factories, Figure 8 present a novel Sustainable Development and Collaboration Framework (SDCF). 


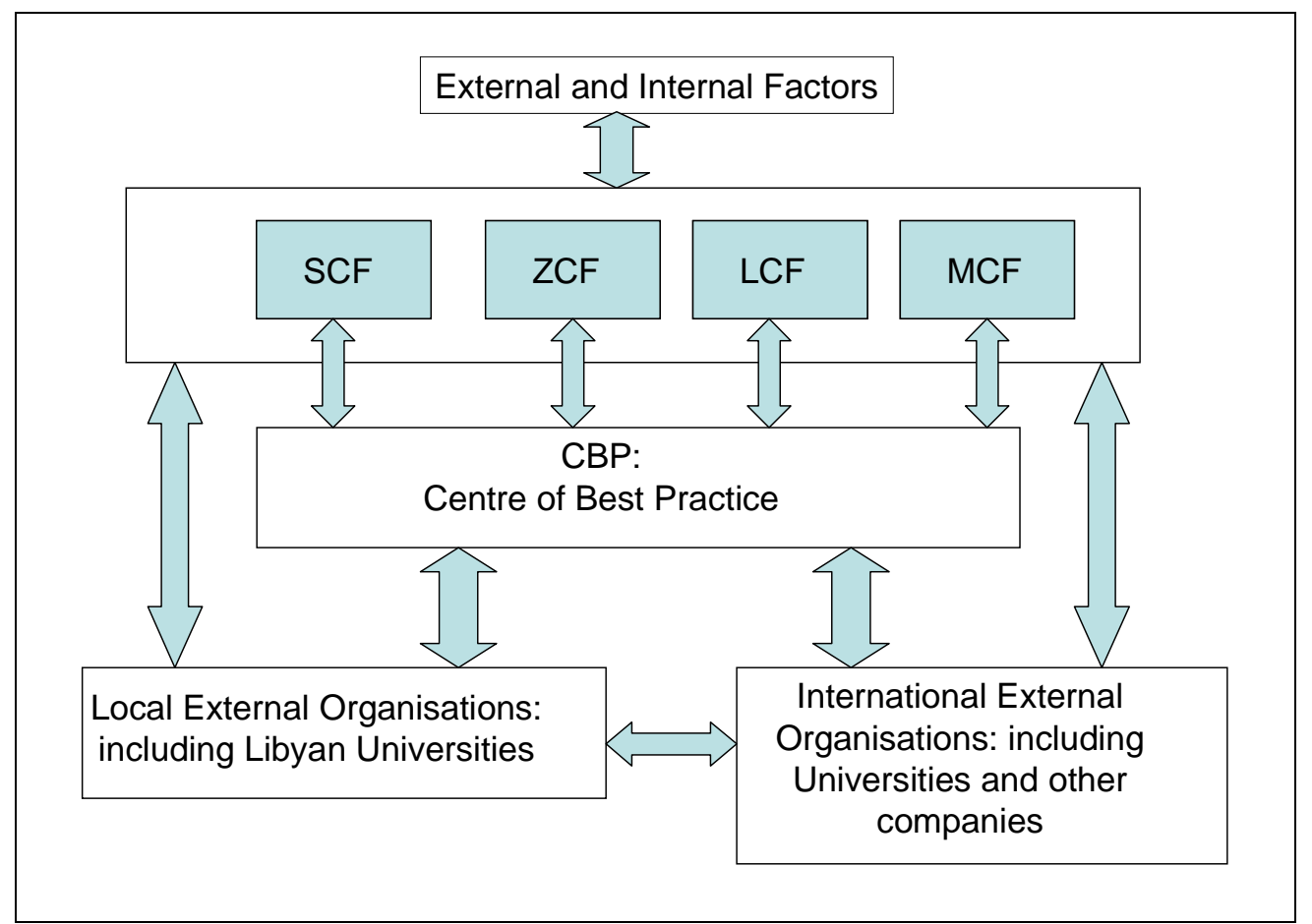

Figure 8: Sustainable Development and Collaboration Framework (SDCF).

This proposed framework is based on establishing a Centre of Best Practice (CBP), this will be the gateway between the company's four factories and the outside environment to capture best practise and suitable training courses from national and international organisations including universities and other colleges.

\section{Conclusions}

The driving force behind this work is the desire of the Libyan cement industry to improve its productivity and profitability. The outcomes of the statistical analysis, field surveys, questionnaires and interviews all agree on the fact that there are many drawbacks in the current situation in the factory in terms of productivity, maintenance, health and safety, and environmental issues. From the statistical analysis, it has been found that the four factories have much less production than the designed capacity, given that there is high need in the market for cement and Libya is currently importing cement from abroad. Moreover, there are high levels of fluctuation in the production of the factories over the years. The main findings of the questionnaire is the lack of training (operational and maintenance), lack of incentives for improvements, the lack of personal development system. In general health and safety response is found to be better than other areas within the factory. The interviews have confirmed some of the major issues in relation to training, financial incentives, pollution measurements and lack of social activities. This is also has been confirmed by the interviews and data analysis. A new framework has been suggested to solve the problems presented in this paper. 


\section{References}

Al-Habaibeh, A.; Parkin,R.M.;Jackson, M.R.;Whitby,D.R.;Mansi,M and Coy, J.(2002), "The Application Of An Autonomous Low Cost Infra-red Thermal Imager For Condition Based Maintenance Of Machinery", Mechatronics 2002 conference, Netherlands, June 2002.

Al-Habaibeh, A. and Parkin, R.M.(2005), "An Evaluation of a Heat Transfer Process Using Sensor Fusion of Thermocouples and InfraRed Thermography", Proceedings of the International Conference on Condition Monitoring 2005 , Kings College, Cambridge, 18th July 2005, pp. 229-233, ISBN: 1-90189-18-2

Al-Habaibeh,A.; Cai,R.; Jackson,M.R.; and Parkin, R.M.(2004), "Modern Development in Sensor Technology and its Applications in Condition Monitoring", Invited Keynote paper, Abstract accepted for the $7^{\text {th }}$ International Conference On Monitoring And Automatic Supervision In Manufacturing, Zakopane, Poland, 19 - 21 August 2004

Ahuja, I.P.S. and Khamba, J.S. (2008), " An evaluation of TPM initiatives in Indian industry for enhanced manufacturing performance", International Journal of Quality \& Reliability Management Vol. 25 No. 2, 2008 pp. 147172.

Ahuja,I.P.S. and Kumar,P. (2009), " Reviews and case studies A case study of total productive maintenance implementation at precision tube mills", Internal of Quality in Maintenance Engineeing Vol. 15 No. 3,2009 pp.241-258.

Al-Muhaisen, M. and Santarisi, N. (2002), "Auditing of the maintenance system of Fuhais plant/Jordan Cement factories Co", Journal of Quality in Maintenance Engineering, Vol. 8 No. 1, 2002, pp.62-76.

Alsyouf, I (2009), “Maintenance practices in Swedish industries: Survey results”, Int. J. Production Economics 121 (2009) 212-223.

Bamber, C.J.; Sharp, J.M.; Hides,M.T (1999), "Factors affecting successful implementation of total productive maintenance - A UK manufacturing case study perspective", Journal of Quality in Maintenance Engineering Volume 5 Number 31999 pp. 162-181.

Bindra, S.P. and Hokoma, R. (2004 ), "Challenges \& opportunities of automobile pollution control in developing countries ", Proceedings of the International Conference on Industrial and Commercial Use of Energy Conference 2004, Western Cape, South Africa, pp . 197-202.

Chan, F.T.S.(2005), "Implementation of total productive maintenance: A case study", International Journal of Production Economics, Volume 95, Issue 1, 28 January 2005, Pages 71-94.

Hokoma, R.A.; Mohamed, K. and Khalid, H.(2008), "Investigation into the implementation stages of manufacturing and quality techniques and philosophies within the Libyan cement industry" Journal of Manufacturing Technology Management, Vol.19N0.7, pp.893-907.

Hokoma,R.A. and Khan, M.K. (2006), " Strategic impact of JIT technique for reducing the storge \& eliminating the waste within petroleum industry ", proceeding of the $9^{\text {th }}$ Mediterranean Petroleum Conference and Exhibition , Tripoli , Libya,pp.152-165. 
Kacprzynski,G.J and M.R.(2000), "Health management strategies for 21st century condition-based maintenance systems", proceedings of 13th International Congress on COMADEM. 2000. Houston, TX, USA.

Kegg, R. L. (1984), “ On-line Machine Process diagnostics”, Ann CIRP, Vol. 32. No. 469, 1984.

Khamba, J.S. and Ahuja I.P.S. (2008), " Total productive maintenance:

Literature review and directions", International Journal of Quality \& Reliability Management Vol. 25 No. 7, 2008 pp. 709-756.

Marcus, B.(2004), Mälardalen University, Sweden, Condition Based Maintenance System Technology -Where is Development Heading?, Euromaintenance 2004 - Proceedings of the 17th European Maintenance Congress, 11th - 13th of May, 2004, AMS (Spanish, Maintenance Society), Barcelona, Spain, B19.580-2004.

Rod, G.; Ron, F. and Kaoru, K.(2008 ), " Japanese context: an integrated management system ", Management Decision Vol. 46 No. 4, 2008 pp. 565579.

Sharma, R.K; Kumar, D. and Kumar, P. (2006), 'Manufacturing excellence through TPM implementation: a practical analysis" Industrial Management \& Data Systems, Volume 106 Number 22006 pp. 256-280

Shamsuddin, A.; Masjuki, H.; and Zahari, T. (2005), " TPM can go beyond maintenance: excerpt from a case implementation", Journal of Quality in Maintenance Engineering Vol. 11 No. 1, 2005 pp. 19-42.

Tsarouhas, P. (2007), “ Reviews and case studies Implementation of total productive maintenance in food industry: a case study", Journal of Quality in Maintenance Engineering Vol. 13 No.1, 2007 pp.5-18. 